\section{Dementia Nomenclatorica Americana}

UNDER the above heading, I wrote to NATURE of November 16, 1935, expressing consternation at the ever-increasing hypertrophy in the nomenclature of the Foraminifera. I have continued to correspond with my friend Dr. H. E. Thalmann, and it may interest readers of NATURE to note that, in the last six years, more than two thousand papers have been published upon these Protozoa. These papers give us sixty new families and sub-families, two hundred new genera and sub-genera, and two thousand four hundred new species and varieties. This gives us two to three new genera per month, and two new species per day.

The brain reels and the senses gape at what might be an even partially complete synonymy to-day, and with what the systematists will be confronted in, say, another six years is not pleasant to contemplate.

Editors (and others) might do worse than establish a rule to the effect that henceforward no synonyms shall be allowed other than those immediately following d'Orbigny, and up to and including $\mathbf{H}$. B. Brady and his contemporaries.

And-to adopt the terminal terminology of Acts of Parliament : "The Conchyliologie Systématique of Denys de Montfort is hereby repealed."

Since the above was written I have received from Java a paper upon "a second species of Biplanispira, etc." This starts a new group of specific names. May we hope before long to add to our nomenclature, Monoplanulina, Hydroplanispira, Junkeria, Fokkerinoides, Handley-Paginella, and de Havillandia? At any rate this would immortalize men who have left the impress of their names upon science, and convey more to posterity than the too-familiar collaborators, who for lack of early literature give us, in turn, Smithia jonesii and Jonesia smithii for slightly differing forms of Truncatulina variabiliswhich is no longer Truncatulina, but has turned Cibicides in a single night.

Edward Heron-Allen.

British Museum (Natural History), S.W.7.

\section{'Convergent' Sunbeams}

From observations made on three different occasions during past few summers, I can corroborate in every detail 'convergent' sunbeams reported by J. J. Hopfield ${ }^{1}$. Always in the late afternoon, the sun just having set behind the Jura and sending out 'fan-like' beams of alternating light and shade, there seemed to be issuing from the opposite horizon behind the Savoyard Mountains (Mont Blanc) similarly radiating beams. Though somewhat faint overhead, the continuous course of these bundles could be clearly traced between the eastern and western horizon.

Only recently a friend told me that flying over Mexican waters about a $1,000 \mathrm{ft}$. up during the solar eclipse he found himself to be the centre of converging beams from the corona.

Les Terrasses,

ArNold C. Klebs.

Nyon (Lake Geneva).

1 NATURE, 141, 333 (1938).
THE striking phenomenon reported by Dr. J. J. Hopfield $^{1}$ is occasionally seen in Great Britain. I have witnessed two excellent examples, one on June $24,1935^{2}$, and another on September $12,1936^{3}$, at Hastings. Mr. W. L. Baxter has recorded a similar occurrence on March 17, 1934, at South Farnborough, Hants ${ }^{4}$. In two of the cases mentioned, the sun had set 20-25 minutes previously. The rays were pale rose or delicate pink in two of these records and orangeyellow in the remaining one, and were of considerable width. The rays extended completely across the sky from north-west to south-east on June 24, 1935, and from west to east on September 12, 1936, and convergence due to perspective was extremely well and strikingly seen. These rays are perhaps more likely to be observed in thundery weather when hard and well-defined cumulus clouds may be ranged low down on the horizon (or even below the horizon) so that protuberances on the cloud throw shadows much in the same way as is commonly seen when the sun is shining brightly behind well-defined cumuli during the daytime. In the latter case rays may be both projected upwards and radiating from the sun as a centre if the cloud is large and unbroken and with a hard summit, or projected downwards to the ground (a much commoner occurrence) if there are breaks or holes in the cloud sheets.

In connexion with the latter example it was an old idea that these rays meant coming rain, and an old saying, "The sun is getting up his back stays, and it is time to look out for bad weather" refers to this ; also these rays gave ris to a saying that the "Sun is drawing water" and rain will soon follow.
39 Clive Avenue, Clive Vale, Hastings.
1 NATURE, 141, 333 (1938).
Met. Mag., 70, 158 (1935).
Met. Mag., 71, 210 (1936).
+ Met. Mag., 69, 119 (1934).

The necessary conditions for the phenomenon of convergent sunbeams are a slight haze spread evenly overhead, and a few small cumulus clouds on the eastern horizon. The best example that $I$ have seen was at sea while travelling from Cape Town to Durban at Easter 1899. By good fortune, Mr. R. T. A. Innes, then secretary of the Cape Observatory, and others were on board, and there was opportunity for careful observation and comparison of notes.

There was a beautiful sunset; cloud shadows radiated from the sun, converging toward a point as far below the horizon as the sun was above it. As the sun set this point rose and the rays met at the eastern horizon. Long bands of pink and blue arched over our heads and over most of the sky like markings of a huge melon. One could have sworn that they were curved-obviously curved-but they were really straight and parallel. A drawing or photograph of any small portion of the sky would have shown straight lines. To the north, south or overhead they would have been parallel, to the east or west they would have been straight but converging. After the sun had set, the converging point rose and a solidlooking blue band touching it, rose too. This was the shadow of the earth, which may often be seen in the east after sunset.

If there is a cloud partly within the band, and partly illuminated by the sun, its height may be calculated. I remember discussing this with Mr. Innes 